\title{
Comparing technical efficiency of farms with an automatic milking system and a conventional milking system
}

\author{
W. Steeneveld, ${ }^{* 1}$ L. W. Tauer, $†$ H. Hogeveen, ${ }^{*} \ddagger$ and A. G. J. M. Oude Lansink ${ }^{\star}$ \\ ${ }^{*}$ Chair group Business Economics, Wageningen University, Wageningen, the Netherlands \\ †Cornell University, Charles H. Dyson School of Applied Economics and Management, Ithaca, NY 14853 \\ ‡Department of Farm Animal Health, Faculty of Veterinary Medicine, Utrecht University, Utrecht, the Netherlands
}

\begin{abstract}
Changing from a conventional milking system (CMS) to an automatic milking system (AMS) necessitates a new management approach and a corresponding change in labor tasks. Together with labor savings, AMS farms have been found to have higher capital costs, primarily because of higher maintenance costs and depreciation. Therefore, it is hypothesized that AMS farms differ from CMS farms in capital:labor ratio and possibly their technical efficiency, at least during a transition learning period. The current study used actual farm accounting data from dairy farms in the Netherlands with an AMS and a CMS to investigate the empirical substitution of capital for labor in the AMS farms and to determine if the technical efficiency of the AMS farms differed from the CMS farms. The technical efficiency estimates were obtained with data envelopment analysis. The 63 AMS farms and the 337 CMS farms in the data set did not differ in general farm characteristics such as the number of cows, number of hectares, and the amount of milk quota. Farms with AMS have significantly higher capital costs (€12.71 per $100 \mathrm{~kg}$ of milk) than CMS farms (€10.10 per $100 \mathrm{~kg}$ of milk). Total labor costs and net outputs were not significantly different between AMS and CMS farms. A clear substitution of capital for labor with the adoption of an AMS could not be observed. Although the AMS farms have a slightly lower technical efficiency (0.76) than the CMS farms (0.78), a significant difference in these estimates was not observed. This indicates that the farms were not different in their ability to use inputs (capital, labor, cows, and land) to produce outputs (total farm revenues). The technical efficiency of farms invested in an AMS in 2008 or earlier was not different from the farms invested in 2009 or 2010, indicating that a learning effect during the transition period was not observed. The results indicate that the economic performance of AMS
\end{abstract}

Received February 28, 2012.

Accepted August 15, 2012.

${ }^{1}$ Corresponding author: wilma.steeneveld@wur.nl and CMS farms are similar. What these results show is that other than higher capital costs, the use of AMS rather than a CMS does not affect farm efficiency and that the learning costs to use an AMS are not present as measured by any fall in technical efficiency.

Key words: automatic milking, dairy, data envelopment analysis, technical efficiency

\section{INTRODUCTION}

The number of dairy farms using an automatic milking system (AMS) is increasing rapidly, especially in northwest Europe. The first AMS was introduced on commercial dairy farms in the Netherlands in 1992, and by the end of 2009, over 8,000 commercial farms worldwide used one or more AMS (de Koning, 2010). In the Netherlands, almost 2,000 farms (10\%) have an AMS (de Koning, 2010), and that number continues to increase.

Research on the economic consequences of using an AMS and the economic comparisons between farms with an AMS and a conventional milking system (CMS) have been mainly based on normative models, and focused on the profitability of the investment. Hyde and Engel (2002) found that the investment in automatic milking was cost effective. In contrast, the study by Dijkhuizen et al. (1997) concluded that investment in an AMS was not cost effective, and Rotz et al. (2003) concluded that an AMS does not offer an economic benefit for most farm scenarios in the United States. These normative models use different methods and assumptions and are completed for different countries. The only empirical economic comparison between farms with an AMS and CMS was conducted by Bijl et al. (2007) who concluded, based on data from 2003, that CMS farms had more money available for rent, depreciation, interest, labor, and profit than AMS farms. Since that time no additional economic comparisons based on empirical research have been reported. These limited and conflicting results, based on a large difference in assumptions, make it difficult to determine whether AMS are good investments. 
Changing from a CMS to an AMS necessitates a new management approach (Svennersten-Sjaunja and Pettersson, 2008) and a corresponding change in labor tasks. Milking with an AMS eliminates some labor tasks, but new labor tasks are required, including control and cleaning of the AMS, 2- or 3-times-per-day checking of attention lists, visual control of the cows, and fetching cows that exceeded maximum milking intervals. Field data on labor savings is limited. In a study on 107 AMS farms in Belgium, Denmark, Germany, and the Netherlands (Mathijs, 2004), labor savings recorded were around $20 \%$ on average, with a large variation among farms reported. Farmers adopting an AMS need time to transition to these new labor tasks. Therefore, it is expected that labor savings may only occur after an extended adjustment period, and that a learning effect might be observed over this period. Together with labor savings, AMS farms have been found to have higher capital costs, primarily because of higher maintenance costs and depreciation (Bijl et al., 2007). These adjustments suggest that economic efficiency may decrease with the adoption of an AMS, at least in the short run.

Because of the expected substitution of capital for labor on farms with the adoption of an AMS, it is expected that AMS farms differ from CMS farms in capital:labor ratio and possibly their technical efficiency, at least during a transition learning period. Previous research has not determined whether adoption of an AMS empirically results in the substitution of capital for labor. Although technical efficiency of dairy farms have been measured previously (e.g., Oude Lansink et al., 2002; Bravo-Ureta et al., 2007; Stokes et al., 2007), no emphasis has been placed on the differences in efficiency among dairy farms with an AMS and CMS, and on the impact on efficiency of adoption of a significant new technology.

The first objective of this study was to compare quantities of labor and capital of farms with a CMS with those using an AMS to determine if empirical substitution of capital for labor has occurred from CMS to AMS. The second objective was to estimate and compare the technical efficiency of farms with an AMS with those using a CMS. In addition, we investigated whether technical efficiency is different for recent adopters and mature adopters of AMS. These objectives were met by the empirical analysis of farm accounting data.

\section{MATERIALS AND METHODS}

\section{Data}

Data for this study originated from a Dutch accounting agency (Accon AVM, Leeuwarden, the Netherlands). This agency is one of the largest farm account- ing agencies in the Netherlands, and their clients can be characterized as farms who are interested in getting information about their financial performance to assist in making enhanced management decisions. A database was available containing farm accounting data from the year 2010 for 408 Dutch dairy farms (primarily from the north of the country) having either an AMS or a CMS. Three farms were excluded because of incomplete information on labor, 1 farm was excluded because of reporting an extremely small quota quantity in comparison with the other farms in the data set, and 4 farms with an AMS were excluded because these farms had an average of 125 cows per automatic milking unit, which can be an indication of incomplete adoption of automatic milking, as each AMS unit cannot milk the number of cows recorded. The final data set consisted of 400 dairy farms (63 AMS farms and 337 CMS farms). From the 63 farms having an AMS, 9 had invested in 2010, 3 had invested in 2009, and 45 had invested in 2008 or earlier. For 6 AMS farms, information on the year of investment was not available.

The database included information on revenues (e.g., revenues from milk and other farm activities), depreciation (e.g., on buildings and machinery), fixed costs (e.g., costs for maintenance of buildings and machinery), variable costs (e.g., costs for feed, breeding, energy, and water), and general farm information such as the number of cows, number of hectares, amount of the milk quota, and the available full-time employees (FTE). All revenues and costs are expressed per $100 \mathrm{~kg}$ of milk (by using the total amount of the milk quota), and subsequently these numbers were analyzed with a $t$-test to compare CMS and AMS farms. General farm information was analyzed with a $t$-test to compare CMS and AMS farms. Data preparation and the analysis were performed using SAS version 9.2 (SAS Institute Inc., Cary, NC).

\section{Hypotheses}

One of the most important reasons to invest in an AMS is the wish for more flexible working hours and more free time (Mathijs, 2004). Previous research indeed reported labor savings on farms with an AMS (Sonck, 1995; Mathijs, 2004) and, therefore, it was hypothesized that after adoption of an AMS the total labor costs would decrease. At the same time, however, it was hypothesized that the capital costs would increase after adoption of an AMS, especially due to higher costs for maintenance and depreciation. This expected shift in the capital:labor ratio can be described as the substitution of capital for labor. This expected substitution is presented graphically in Figure 1 where the labor costs and capital costs are shown for a col- 
lection of farms that use an AMS or a CMS. It was expected that the CMS farms because of higher labor and lower capital costs would mainly be observed in the bottom right corner of the graph, and that the AMS farms because of lower labor and higher capital costs would mainly be observed in the upper left corner of the graph. Changing to automatic milking coincides with a change in daily working activities, leading to more attention for checking of cows and interpretation of sensor outcomes. It was expected that dairy farmers would have to adjust to these new daily working activities and routines and that labor savings might not happen immediately after adoption. Therefore, it was expected that recent adopters in comparison with non-recent adopters would have a lower efficiency and, therefore, would be observed mainly at the right side. Due to an expected learning effect, efficiency might go up after the adoption and the farms might shift to the left side of the graph.

\section{Data Envelopment Analysis}

The technical efficiency of the farms was identified using data envelopment analysis (DEA), which is a nonparametric method of calculating the efficiency of individual decision-making units (DMU). Data envelopment analysis compares the levels of inputs and outputs for a given DMU against all other DMU in the data set to determine which DMU are producing at efficient levels relative to the entire group. The concept of DEA efficiency can best be illustrated with a simple example (Figure 2). Herds A, B, and C are DEA efficient, as they use the least amount of labor and capital

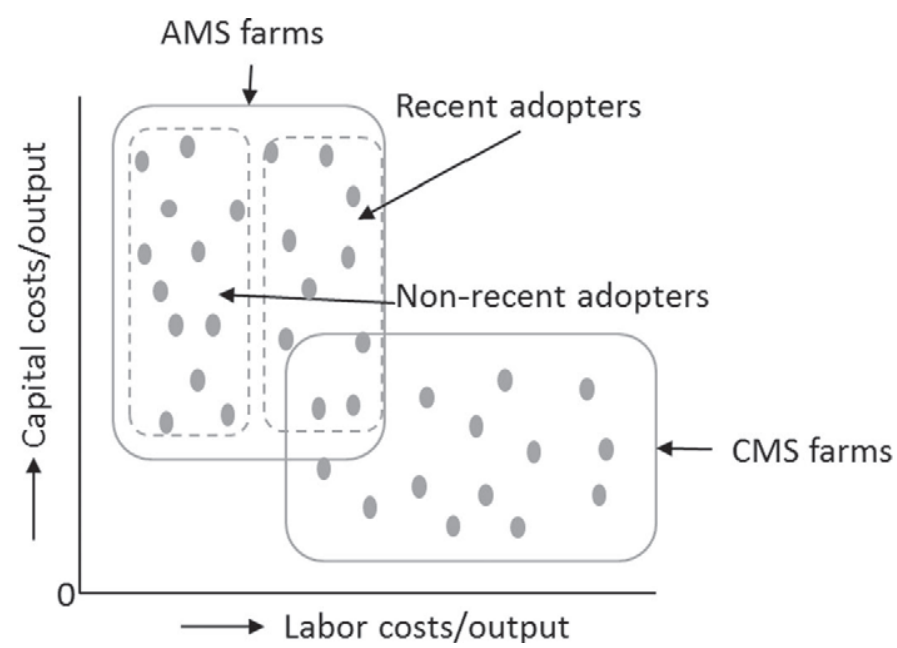

Figure 1. Hypothesized situation of farms with a conventional milking system (CMS) or an automatic milking system (AMS) regarding the distribution of the labor and capital costs. to produce 1 unit of output. The line connecting A, $\mathrm{B}$, and $\mathrm{C}$ is called the efficient frontier. An estimate of technical efficiency can be obtained for each herd by projecting a ray from the origin to each herd point, such as point D. An estimate of technical efficiency is then calculated as the ratio of the distances from the origin to point $\mathrm{x}$, divided by the distance from the origin to point $\mathrm{D}$. An efficiency estimate is between 0 (inefficient) and 1 (efficient), and indicates the percentage by which both inputs of an efficient DMU could be lower to produce the same level of output as an inefficient DMU (Cooper et al., 2000). For example, an efficiency of 0.80 would imply that the use of each input is lower by $20 \%$ for DEA efficient production. Although Figure 2 uses only 2 inputs and 1 output for illustrative purposes, the DEA concept can be applied to production involving any number of inputs and outputs.

One of the main drawbacks of the DEA is that its results may be affected by the sampling variation, suggesting that distances to the frontier are likely to be over- or underestimated. To assess the sampling variability of the results, 95\% confidence intervals were constructed using the bootstrap algorithm specified in Simar and Wilson $(1998,2000)$. The basic idea of the bootstrap algorithm is that if the data are viewed as a set of random draws from an underlying population, random draws from the sample are also random draws from the population. Therefore, the known bootstrap

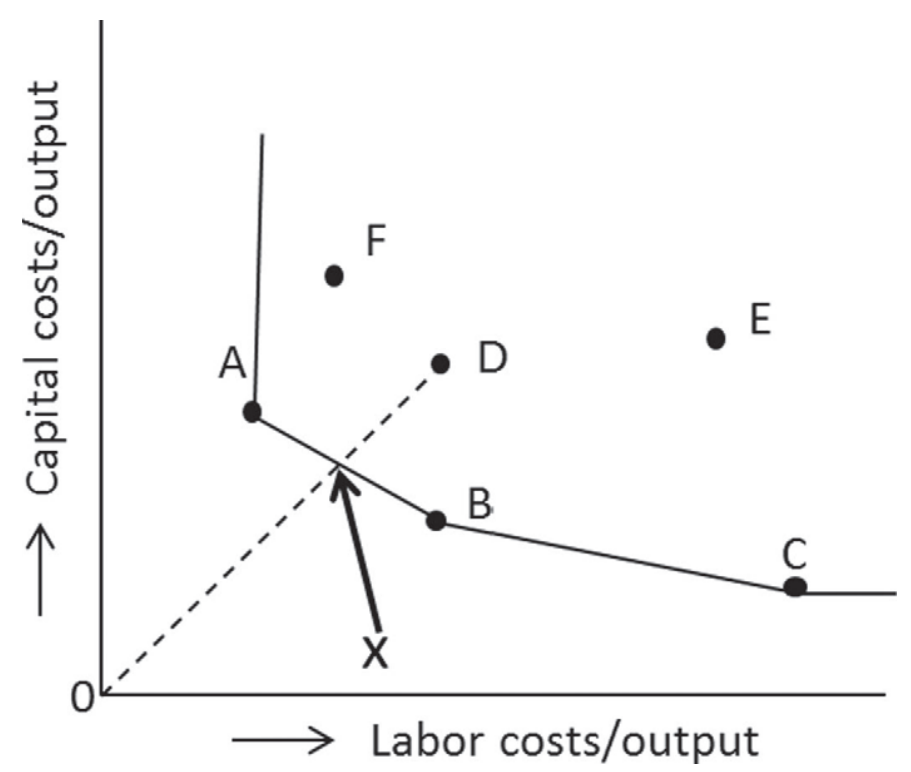

Figure 2. Example of a data envelopment frontier for 6 farms using labor and capital as inputs and producing 1 output. Farms A, $\mathrm{B}$, and $\mathrm{C}$ have the lowest combination of labor and capital costs and, therefore, form the frontier. The technical efficiency of farm D was calculated as the ratio of the distances from the origin to point $\mathrm{x}$, and the origin to point $\mathrm{D}$. 
distribution will mimic the original unknown distribution if the known data-generating process is a consistent estimator of the unknown data-generating process. After many simulations, a distribution of efficiency scores is obtained and represents an estimate of the true distribution.

To allow capital for labor substitution and learning inefficiencies using an AMS, DEA efficiencies were estimated. The capital items were defined as the number of cows, total number of hectares used by the dairy farm, and other total capital costs, and then total labor costs were defined as input variables. All other inputs were subtracted from output to arrive at a net output consisting of output minus materials. Total capital costs included all expenses and depreciation on buildings, machinery, and equipment. Total labor costs included the costs for customer work, paid labor, and calculated costs for own labor, which was calculated by using the available FTE and assuming $52 \mathrm{wk}, 40 \mathrm{~h}$ per week, at the rate of $€ 18 / \mathrm{h}$ (Huijps et al., 2008). The net outputs of the farm were calculated by summing all revenues from farm activities (milk revenues, livestock revenues, revenues from other farm activities, and miscellaneous revenues) minus the total costs for materials, such as costs for feeding, breeding, healthcare, energy, and water. Because total feed costs were not different between AMS and CMS farms and to save degrees of freedom in the DEA model, we decided to include feed not as a separate input but to take it into account in the net output.

All calculations on the technical efficiency were performed using the statistical computing software $\mathrm{R}$ (The R Foundation for Statistical Computing, Vienna, Austria), which was supplemented by the efficiency computational software library FEAR 1.0 (Wilson, 2008). For calculating the efficiency estimates, an input orientation model with a single output and 4 inputs was applied using a variable returns-to-scale assumption. The FEAR software allows bootstrapping results and adjusting for bias estimates (because of the upper bound of 1.00 on efficiency) as presented in Simar and Wilson (1998). For this study, 2,000 bootstraps were run. The model determined the technical efficiency of each farm $j$ with the following linear programming problem:

$$
\begin{gathered}
\min \theta_{j} \\
\theta_{j} \mathrm{x}_{j m} \geq \mathrm{x}_{k m} \boldsymbol{\lambda}_{j k} \\
\mathrm{y}_{k i} \boldsymbol{\lambda}_{j} \geq \mathrm{y}_{j i} \\
\boldsymbol{\lambda}_{j} \geq 0,
\end{gathered}
$$

where $\theta_{j}$ is the measure of technical efficiency of the $j$ th farm and $\boldsymbol{\lambda}$ is an $\mathrm{n} \times 1$ vector of constants. In equation $1, m$ are the inputs so that $\mathrm{x}_{j m}$ is the amount of input $m$ used by DMU $j$ and $x_{k m}$ is the amount of input $m$ used by each of the other $k$ DMU. Also, $i$ are the outputs so that $\mathrm{y}_{j i}$ represents the amount of output $i$ produced by DMU $j$ and $\mathrm{y}_{k i}$ is the amount of output $i$ produced by each other of the other $k$ DMU. The linear program above is solved once for each DMU, so that efficiency is gauged for each DMU $j$ relative to each of the other $k$ DMU in the sample.

\section{RESULTS AND DISCUSSION}

Annual economic reports are generally of interest to farmers who have a special interest in their financial performance. The farms in our sample can, therefore, be characterized as farms who are interested in getting information about their financial performance to assist in making enhanced management decisions. Therefore, it is not unexpected that smaller farms were not common in the data (Table 1) and that total land use, total milk quota, and number of cows were higher than the current Dutch average (CBS, 2010). However, total land use, milk quota, total FTE, and number of cows did not differ between the AMS and CMS farms (Table 1). Because of this observation, all farms were included in one data set for calculation of the technical efficiency scores, and differences in the technical efficiency scores can be interpreted as the result of variables not included in the DEA model, most likely the milking system used.

The number of FTE was not different between AMS and CMS farms (Table 1), which is in contrast with the results of Bijl et al. (2007) who found a lower number of FTE on AMS farms. A possible explanation for this difference could be that the farmers who invested in 2003 (Bijl et al., 2007) invested to lower the amount of labor and to have more free time, as described by Mathijs (2004). Farms in the current data set may be more focused on increasing size than on having more free time, thus showing no decrease in FTE as they plan and transition to more cows. Many more dairy farmers now may be focused on increasing their herd size than in 2003 because of the announced abolishment of the milk quota in 2015 and the expected need to increase in size to remain profitable after that year. This movement to an increased size probably means that any released labor when starting automatic milking is put into other farm activities that coincides with size increase. As a result, there was no decrease in FTE on the observed AMS farms. Unfortunately, the data set did not include any information about possible expansion plans and, therefore, this explanation could not be confirmed. Another explanation for the almost equal 
Table 1. Overview of general farm information of farms with an automatic milking system (AMS) and a conventional milking system (CMS)

\begin{tabular}{|c|c|c|c|c|c|}
\hline Item & \multicolumn{2}{|c|}{$\operatorname{AMS}(\mathrm{n}=63)$} & \multicolumn{2}{|c|}{ CMS $(\mathrm{n}=337)$} & $P$-value \\
\hline Total land use (ha) & 71 & 27.9 & 70 & 28.1 & 0.77 \\
\hline Milk quota (kg) & 897,426 & 384,368 & 903,827 & 376,747 & 0.90 \\
\hline No. of dairy cows & 110 & 42 & 113 & 47 & 0.68 \\
\hline Milk per cow $(\mathrm{kg})$ & 8,297 & 980 & 8,111 & 809 & 0.11 \\
\hline Total labor $\mathrm{FTE}^{1}$ & 1.54 & 0.51 & 1.51 & 0.47 & 0.62 \\
\hline Cow/FTE & 74 & 24.9 & 78 & 28.1 & 0.36 \\
\hline Milk/FTE (kg) & 597,615 & 214,588 & 622,947 & 266,836 & 0.48 \\
\hline
\end{tabular}

${ }^{1} \mathrm{FTE}=$ full-time employee.

FTE could be that labor savings after adoption of an AMS are not as large as first expected. It is clear that some labor requirements are reduced, but those may be replaced with other increased labor requirements, which results in the net labor change being ambiguous. Comprehensive recent field data on possible labor savings is lacking (Sonck, 1995; Mathijs, 2004). In addition, the FTE estimated available in the current data set were provided by the farmers themselves and these farmers may record a full FTE regardless of the actual hours worked each year, which may be reduced with an AMS but still considered full time by most. Therefore, given these considerations, it is difficult to conclude, based on the information on FTE in the current database, whether adoption of AMS led to a decrease in labor used. One of the most important reasons to adopt automatic milking is the more flexible working hours that can result (Mathijs, 2004). Labor on the farms in the current data set might be more flexible, but information on whether labor is in fact more flexible was not available and is moreover difficult to quantify.

Table 2 shows an overview of the inputs and output for the 337 CMS and 63 AMS farms. The capital and labor inputs and the output were expressed per $100 \mathrm{~kg}$ of milk to allow comparison across farms. As expected, the total capital costs of AMS farms were significantly higher than for CMS farms. These higher capital costs were mainly due to higher expenses and depreciation on machinery and equipment. These expenses are mostly greater due to the higher maintenance costs because of high replacement rates of AMS. The depreciation is higher not only because of the cost of an AMS but also because AMS units may have shorter economic lives than CMS. No reliable estimates are available, however, on the economic lifespan of an AMS, and it would be beneficial to collect and analyze the actual economic lifespan of AMS to allow more reliable comparisons with CMS farms. Surprisingly, the costs for substitutes for concentrates and milk products were significantly different between AMS and CMS farms, and no explanation for this difference is obvious. The AMS farms had, as expected, significantly higher costs for energy and water ( $€ 1.58$ per $100 \mathrm{~kg}$ of milk) than the CMS farms (€1.22 per $100 \mathrm{~kg}$ of milk). As a consequence of not finding a difference in FTE between the AMS and CMS farms, owner labor costs were also not much different between AMS and CMS farms. It was expected that after adoption of an AMS paid labor costs would decrease because these are direct and cash costs for the dairy farmer, in contrast with the owner labor costs; the results indicate that paid labor costs were, on average, almost $€ 0.24$ per $100 \mathrm{~kg}$ of milk lower for AMS farms, but the difference with CMS farms was not significant. Costs for paid labor consists of the expenses of people working (temporarily) on the farm, including household members. No differences were observed between the AMS and CMS farms in outputs sold or net outputs. The total revenue for AMS and CMS farms were $€ 44.87$ and $€ 45.33$ per $100 \mathrm{~kg}$ of milk, respectively, and net outputs for AMS and CMS farms were $€ 27.70$ and $€ 28.34$ per $100 \mathrm{~kg}$ of milk. So, from Table 2 it can be seen that AMS farms have higher capital costs, but the net outcome is not different between CMS and AMS farms. This means that small nonsignificant differences of labor and material costs compensate for the higher capital costs of AMS farms.

Previously, results from normative studies showed that investments in AMS were not cost effective for the Netherlands (Dijkhuizen et al., 1997) and the United States (Rotz et al., 2003). Based on farm accounting data of 2003, it was concluded that the gross margins of AMS and CMS farms did not differ, but by also incorporating costs not directly associated with cattle husbandry or land use (e.g., costs for water, electricity, customer work, and maintenance costs for machinery and equipment), it was concluded that CMS farms had 

or a conventional milking system (CMS) in 2010

\begin{tabular}{|c|c|c|c|c|c|c|}
\hline \multirow[b]{2}{*}{ Variable } & \multirow[b]{2}{*}{ Included farm accounting data } & \multicolumn{2}{|c|}{$\operatorname{AMS}(\mathrm{n}=63)$} & \multicolumn{2}{|c|}{ CMS $(\mathrm{n}=337)$} & \multirow[b]{2}{*}{$P$-value } \\
\hline & & Average & $\mathrm{SD}$ & Average & $\mathrm{SD}$ & \\
\hline Cows (no.) & Total number of cows & 71 & 27.9 & 70 & 28.1 & 0.77 \\
\hline Land (ha) & Total land use & 110 & 42 & 113 & 47 & 0.68 \\
\hline \multirow{6}{*}{ Capital costs $(€ / 100 \mathrm{~kg}$ of milk) } & Expenses for buildings & 1.56 & 2.13 & 1.54 & 1.81 & 0.92 \\
\hline & Depreciation on buildings & 2.69 & 2.17 & 2.51 & 2.36 & 0.56 \\
\hline & Expenses for machinery and equipment & 4.57 & 1.33 & 3.48 & 2.82 & 0.0029 \\
\hline & Depreciation on machinery and equipment & 3.88 & 1.86 & 2.53 & 1.75 & $<0.0001$ \\
\hline & Miscellaneous depreciation & 0.01 & 0.05 & 0.04 & 0.32 & 0.47 \\
\hline & Total capital & 12.71 & 3.67 & 10.10 & 6.75 & 0.0030 \\
\hline \multirow[t]{4}{*}{ Labor costs $(€ / 100 \mathrm{~kg}$ of milk $)$} & Customer work & 2.89 & 1.64 & 2.96 & 1.79 & 0.74 \\
\hline & Paid labor & 0.46 & 1.02 & 0.70 & 1.10 & 0.12 \\
\hline & Own labor ${ }^{1}$ & 6.95 & 2.20 & 7.06 & 5.02 & 0.87 \\
\hline & Total labor & 10.30 & 2.57 & 10.72 & 6.08 & 0.59 \\
\hline \multirow[t]{13}{*}{ Materials costs $(€ / 100 \mathrm{~kg}$ of milk) } & Roughage & 0.70 & 0.72 & 0.82 & 0.89 & 0.29 \\
\hline & Concentrates & 6.51 & 1.27 & 6.51 & 2.79 & 0.99 \\
\hline & Substitutes for concentrates & 0.50 & 0.55 & 0.77 & 0.84 & 0.013 \\
\hline & Milk products & 0.29 & 0.26 & 0.22 & 0.19 & 0.011 \\
\hline & Minerals & 0.34 & 0.38 & 0.27 & 0.32 & 0.11 \\
\hline & Fertilizer & 1.12 & 0.42 & 1.26 & 0.83 & 0.18 \\
\hline & Pesticides & 0.30 & 0.46 & 0.22 & 0.36 & 0.096 \\
\hline & Breeding & 0.96 & 0.39 & 0.94 & 0.90 & 0.84 \\
\hline & Health care & 1.26 & 0.50 & 1.22 & 0.94 & 0.69 \\
\hline & Energy and water & 1.58 & 0.50 & 1.22 & 0.64 & $<0.0001$ \\
\hline & Manure removal & 0.07 & 0.18 & 0.09 & 0.28 & 0.56 \\
\hline & Miscellaneous & 3.54 & 1.18 & 3.45 & 3.81 & 0.85 \\
\hline & Total materials & 17.17 & 3.04 & 16.99 & 9.35 & 0.87 \\
\hline \multirow{5}{*}{ Revenues $(€ / 100 \mathrm{~kg}$ of milk) } & Milk revenues & 39.72 & 3.76 & 40.44 & 18.15 & 0.75 \\
\hline & Livestock revenues & 2.97 & 1.52 & 2.96 & 2.49 & 0.97 \\
\hline & Other farm activity revenues & 1.34 & 2.07 & 1.05 & 2.98 & 0.45 \\
\hline & Miscellaneous revenues & 0.84 & 1.06 & 0.74 & 1.52 & 0.61 \\
\hline & Total revenues & 44.87 & 4.98 & 45.33 & 24.68 & 0.90 \\
\hline Net output $(€ / 100 \mathrm{~kg}$ of milk) & Total revenues - total materials & 27.70 & 4.28 & 28.34 & 15.90 & 0.77 \\
\hline
\end{tabular}

${ }^{1}$ Value was calculated by multiplying the full-time equivalent by $40 \mathrm{~h}$, by $52 \mathrm{wk}$, and by $€ 18 / \mathrm{h}$ (Huijps et al., 2008). 
more money available for rent, depreciation, interest, labor, and profit (Bijl et al., 2007). In that study, depreciation was not taken into account, and if depreciation were taken into account, the difference between AMS and CMS farms would have been even greater. The results of the current study show that, by also including depreciation and costs not directly associated with cattle husbandry or land use, the net output of CMS and AMS farms did not differ (Table 2). These results indicate that the economic performance of AMS and CMS farms were similar in 2010 in comparison with year 2003. This trend might be explained by the improved technical performance of the AMS and improved supervision of farmers that start automatic milking. This small difference in economic performance between AMS and CMS farms might only be true for farms in northwest Europe, with farms with a relative small size and high labor costs. For the United States, the difference in economic performance between CMS and AMS could be larger. The herd size of US dairy farms is larger, requiring multiple AMS units, which will make total investment costs, yearly maintenance costs, and depreciation much higher than for a single CMS. Because labor costs in the United States are lower than in northwest Europe, total labor costs on a CMS farm would logically be lower than all yearly maintenance costs and depreciation when milking with an AMS. However, empirical data would be needed to substantiate these assertions.

In Figure 3, the total labor and capital costs per net output were plotted for the AMS and CMS farms. No specific pattern for the AMS or CMS farms can be seen, and also separate fitted regression lines of the capital:labor ratios through all CMS farms and all AMS farms were almost identical (not shown). Therefore, the hypothesized situation on substitution of capital for labor on an AMS farm (Figure 1) was not observed. The pattern seen in Figure 3 indicates that no big differences in technical efficiency estimates between AMS and CMS farms were found. The difference in technical efficiency was small (Table 3), with an estimate of 0.78 for CMS farms and 0.76 for AMS farms. Using the confidence intervals of both estimates, it must be concluded that this difference is not signifi-

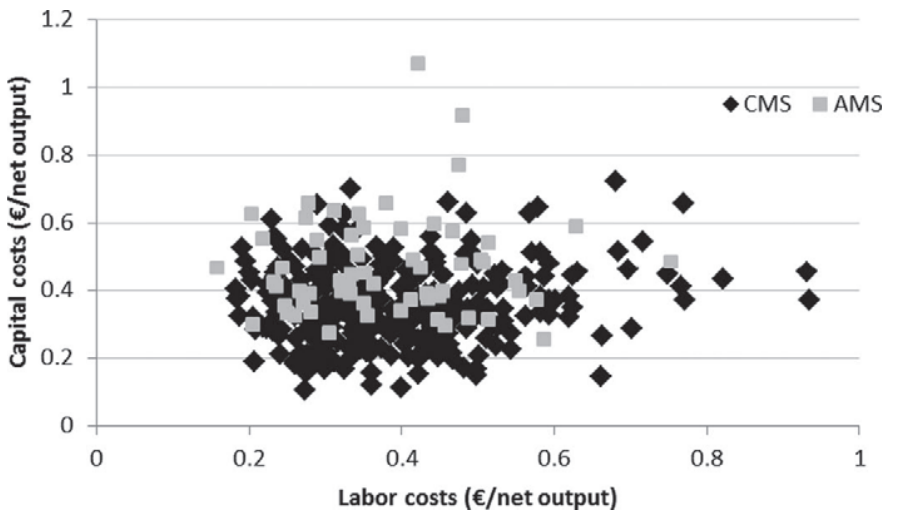

Figure 3. The inputs labor and capital for dairy farms with an automatic milking system (AMS) and those with a conventional milking system (CMS).

cantly different. Not finding the substitution of capital for labor and no difference in technical efficiency was probably caused by the almost equal number of FTE for both types of farms. The observed lower amount of paid labor for AMS farms was relatively small to show a clear substitution of capital for labor.

In Figure 4, labor and capital costs were plotted for different years after investment and adoption of an AMS. No specific pattern was displayed for farms that invested in 2008 or earlier and, therefore, had at least more than 2 yr of experience with AMS. The hypothesized situation discussed earlier and illustrated in Figure 1 was not observed. In addition, a nonsignificant difference was found between the technical efficiency of the farms investing in 2008 or earlier compared with the farms investing in 2009 or 2010 (Table 4). Farms that invested in 2008 or earlier had a technical efficiency of 0.76, and the farms that invested in 2009 or 2010 had a slightly lower technical efficiency of 0.74 . This indicates that a clear learning effect could not be observed using the current data set.

\section{CONCLUSIONS}

The current study used actual farm accounting data from dairy farms in the Netherlands with an AMS or a CMS to investigate the empirical substitution of capital

Table 3. Technical efficiency estimates for farms with an automatic milking system (AMS) or a conventional milking system (CMS)

\begin{tabular}{lccc}
\hline System & Average & Minimum-maximum & $95 \%$ CI \\
\hline AMS $(\mathrm{n}=63)$ & 0.76 & $0.54-0.95$ & $0.73-0.78$ \\
CMS $(\mathrm{n}=337)$ & 0.78 & $0.49-0.97$ & $0.75-0.81$ \\
\hline
\end{tabular}


Table 4. Technical efficiency estimates for farms with an automatic milking system for recent and non-recent adopters

\begin{tabular}{lccc}
\hline Situation & Average & Minimum-maximum & $95 \%$ CI \\
\hline Adopted in 2008 or earlier $(\mathrm{n}=45)$ & 0.76 & $0.54-0.95$ & $0.73-0.79$ \\
Adopted in 2009 or 2010 $(\mathrm{n}=12)$ & 0.74 & $0.64-0.92$ & $0.72-0.76$ \\
\hline
\end{tabular}

for labor in AMS farms and to determine if the technical efficiency of AMS farms differed from CMS farms. The 63 AMS farms and the 337 CMS farms in the data set did not differ in general farm characteristics such as the number of cows, number of hectares, and the amount of the milk quota, allowing unbiased comparison. Farms with AMS had significantly higher capital costs (€12.71 per $100 \mathrm{~kg}$ of milk) than CMS farms (€10.10 per 100 $\mathrm{kg}$ of milk). Total labor costs and net outputs were not significantly different between AMS and CMS farms. A clear substitution of capital for labor with the adoption of an AMS could not be observed. Although the AMS farms had a slightly lower technical efficiency (0.76) than the CMS farms (0.78), a significant difference in these estimates was not observed. This indicates that the farms were not different in their ability to use inputs (capital, labor, cows, and land) to produce outputs (total farm revenues). The technical efficiency of farms investing in an AMS in 2008 or earlier was not different from the farms investing in 2009 or 2010, indicating that a learning effect during the transition period did not occur. The economic performance of AMS and CMS farms were similar. What these results show is that other than higher capital costs, the use of AMS rather than a CMS did not affect farm efficiency and that the learning costs to use an AMS were not present as measured by any decrease in technical efficiency.

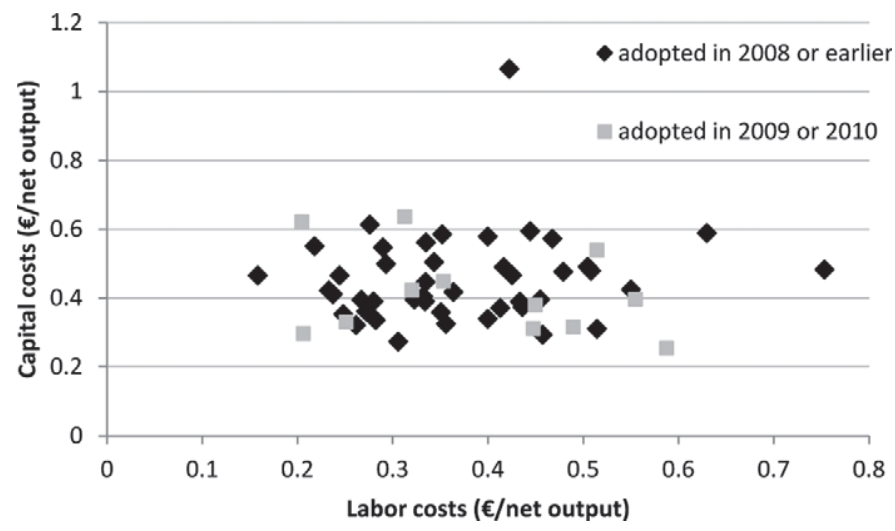

Figure 4. The inputs labor and capital for dairy farms with an automatic milking system for recent and non-recent adopters of automatic milking.

\section{ACKNOWLEDGMENTS}

The authors gratefully acknowledge Accon AVM (Leeuwarden, the Netherlands) for providing the data used in this study. The authors are grateful for the financial support granted by Wageningen School of Social Sciences (Wageningen, the Netherlands).

\section{REFERENCES}

Bijl, R., S. R. Kooistra, and H. Hogeveen. 2007. The profitability of automatic milking on Dutch dairy farms. J. Dairy Sci. 90:239-248.

Bravo-Ureta, B. E., D. Solís, V. H. Moreira López, J. F. Maripani A. Thiam, and T. Rivas. 2007. Technical efficiency in farming: A meta-regression analysis. J. Prod. Anal. 27:57-72.

CBS (Centraal Bureau voor de Statistiek). 2010. Dutch statistical data. Accessed Feb. 7, 2012. http://www.cbs.nl.

Cooper, W. W. L. M. Seiford, and K. Tone. 2000. Data Envelopment Analysis: A Comprehensive Text with Models, Applications, References and DEA-Solver Software. Kluwer Academic Publishers, Boston, MA.

de Koning, C. J. A. M. 2010. Automatic milking-Common practice on dairy farms. Pages 52-67 in Proceedings of the First North American Conference on Precision Dairy Management, Toronto, ON, Canada.

Dijkhuizen, A. A., R. B. M. Huirne, S. B. Harsh, and R. W. Gardner. 1997. Economics of robot application. Comput. Electron. Agric. $17: 111-121$

Huijps, K., T. J. G. M. Lam, and H. Hogeveen. 2008. Costs of mastitis: Facts and perception. J. Dairy Res. 75:113-120.

Hyde, J., and P. Engel. 2002. Investing in a robotic milking system A Monte Carlo simulation analysis. J. Dairy Sci. 85:2207-2214.

Mathijs, E. 2004. Socio-economic aspects of automatic milking. Pages 46-55 in Automatic Milking: A Better Understanding. A. Meijering, H. Hogeveen and C. J. A. M. de Koning, ed. Wageningen Academic Publishers, Wageningen, the Netherlands.

Oude Lansink, A., K. Pietola, and S. Bäckman. 2002. Efficiency and productivity of conventional and organic farms in Finland 19941997. Eur. Rev. Agric. Econ. 29:51-65.

Rotz, C. A., C. U. Coiner, and K. J. Soder. 2003. Automatic milking systems, farm size, and milk production. J. Dairy Sci. 86:41674177.

Simar, L., and P. W. Wilson. 1998. Sensitivity analysis of efficiency scores: How to bootstrap in nonparametric frontier models. Manage. Sci. 44:49-61.

Simar, L., and P. W. Wilson. 2000. A general methodology for bootstrapping in non-parametric frontier models. J. Appl. Stat. 27:779-802.

Sonck, B. R. 1995. Labor research on automatic milking with a human-controlled cow traffic. Neth. J. Agric. Sci. 43:261-285.

Stokes, J. R., P. R. Tozer, and J. Hyde. 2007. Identifying efficient dairy producers using data envelopment analysis. J. Dairy Sci. 90:2555-2562.

Svennersten-Sjaunja, K. M., and G. Pettersson. 2008. Pros and cons of automatic milking in Europe. J. Anim. Sci. 86:37-46.

Wilson, P. W. 2008. FEAR 1.0: A software package for Frontier Efficiency Analysis with R. Socioecon. Plann. Sci. 42:247-254. 